\title{
Prevalence of malnutrition in COPD and its relationship with the parameters related to disease severity
}

This article was published in the following Dove Press journal: International Journal of COPD

\author{
Burak Mete' \\ Erkan Pehlivan' \\ Gazi Gülbaș² \\ Hakan Günen ${ }^{3}$ \\ 'Department of Public Health, \\ Faculty of Medicine, Inönü University, \\ Malatya, Turkey; ${ }^{2}$ Department of \\ Pulmonary Medicine, Faculty of \\ Medicine, İnönü University, Malatya, \\ Turkey; ${ }^{3}$ Sureyyapasa Research and \\ Training Center for Chest Diseases \\ and Thoracic Surgery, Health Sciences \\ University, Ministry of Health, \\ Istanbul, Turkey
}

Objective: The aim of the study was to determine the nutritional status and anthropometric values in a group of patients with COPD and to examine the relationship between these factors and disease severity.

Methods: A total of 105 COPD patients were included in this cross-sectional study. The patients underwent spirometric exmination. Mini nutritional assessment form was applied, and the anthropometric values of the patients were measured by bioelectrical impedance method. Nutrient registration forms were given using a 3-day, 24-hour recall method to assess the nutrient uptake. COPD severity was determined using the Global Initiative for Chronic Obstructive Lung Disease criteria, and the correlations between nutritional status and disease severity parameters were measured.

Results: The prevalence of malnutrition in our patients with COPD was found to be $17 \%$. Spirometric parameters were found to be significantly lower in patients with low body mass index (BMI) and malnutrition. As the modified Medical Research Council dyspnea scale score increased, the frequency of malnutrition increased $(P=0.002)$. Positive significant correlation was found between spirometric variables and muscle mass and fat external tissue volume of the patients. Patients receiving higher protein content in diet showed a better muscle mass amount $(P<0.001)$.

Conclusion: Our study results confirmed that malnutrition is an important and frequently encountered problem in COPD patients, and spirometric values of the patients with malnourishment and with low BMI are significantly lower. We think that nutritional status should be evaluated in every COPD patient, and nutritional intake should be tailored individually.

Keywords: COPD, malnutrition, nutritional status

\section{Introduction}

COPD is one of the leading causes of morbidity and mortality worldwide. Comorbidities are encountered more frequently compared to the same age group and play an important role in the natural course of the disease. Most important comorbidities are hypertension, cardiological and vascular problems, muscular and skeletal abnormalities, neurological and psychiatric problems, and lung cancer. There are many systemic consequences of the disease itself and accompanying clinical conditions. ${ }^{1,2}$

Although malnutrition is an important problem in COPD, it is usually overlooked during the management of patients. About 20\% of COPD patients have weight loss, and protein and calorie malnutrition. The addition of malnutrition to COPD contributes to the impairment of respiratory muscle dysfunction, severity of the disease, and progression of disability. Weight loss, low body weight, and malnutrition in COPD have negative impact on mortality too. ${ }^{3,4}$ 
In this study, we aimed to determine malnutrition prevalence, nutritional status, and anthropometric measurements in a group of patients with COPD in Turkey, and to determine the relationship between these factors and disease severity parameters.

\section{Materials and methods}

This cross-sectional study included outpatients with COPD and the hospitalized patients with COPD referred to the Department of Pulmonary Medicine, Turgut Ozal Medical Center, Inonu University, Malatya, between September and October of 2016. Malatya Clinical Research Ethics Board approved the study protocol (Decision no 2016/169). Written informed consent was obtained from all the patients. Spirometric measurements were performed during stable state, and for the hospitalized patients, the latest stable state spirometric measurements prior to COPD exacerbation were considered. A COPD diagnosis was based on $\mathrm{FEV}_{1} / \mathrm{FVC}$ ratio of $<0.7$, in the absence of a primary diagnosis of bronchiectasis, asthma, or any other significant respiratory disease. The patients also had symptoms and a history compatible with COPD (disease onset after 40 years of age, smoking history of at least 10 packs/year, or occupational exposure to irritant or toxic gases or biomass exposure). After the detailed examination of the patients, the Global Initiative for Chronic Obstructive Lung Disease (GOLD) categories were determined using exacerbation history and modified Medical Research Council (mMRC) dyspnea scale, and a questionnaire was administered to determine various sociodemographic characteristics.

The GOLD 2017 combined assessment method was used to determine the patients' GOLD categories. ${ }^{5}$ The patients were examined in four groups with increasing severity (A, B, C, and D). In the evaluation of the exacerbation status, a frequent exacerbator was determined if hospitalized at least once for COPD and/or had at least two courses of antibiotic and/or systemic steroid treatment due to increased COPD symptoms in the last 12 months.

The questionnaire for nutrition consisted of three parts: the first part was based on the sociodemographic characteristics and the questions about the characteristics of the patients, and the second part comprised the administration of the mini nutritional assessment (MNA) form in which the malnutrition is evaluated, and the third part included the measurement of dyspnea using mMRC dyspnea scale. After these measurements, the waist circumference was measured, and the body composition was determined using the TANITA BF 350 device. After the measurements were made, nutritional registration forms were provided using the 3-day, 24-hour recall method to assess nutrient uptake at home. How the patients should keep the records and on what days they should be filled out was explained in detail. The completed food registration forms were received either directly or via Internet according to the facilities of the patient. The 3-day nutritional values were calculated with BeBIS (Nutritional Information System) program and the averages were taken. The nutrition information system program is a program designed to analyze the nutrient content.

There is no gold standard biochemical method for the detection of malnutrition. Therefore, various methods are used to detect malnutrition. One of the most widely used methods among these is the MNA test. The MNA was developed in cooperation with the University of Toulouse, the New Mexico Medical School and the Swiss Nestle Research Center in 1994, and validity and reliability study in our country was conducted by Sarikaya in $2013 .{ }^{6}$ The original MNA includes questions about general health status, nutrition, anthropometry, and the patient's self-assessment. The long MNA contains 18 items collected in four sections. These four sections are: anthropometric evaluation (body mass index [BMI], weight, and arm and calf circumferences); general evaluation (lifestyle, drug, mobility, depression, and dementia indications); short nutritional evaluation (number of meals, intake of food and fluid, and autonomy to nutrition); and subjective assessment (self-perception of health and nutrition). According to the answers given to 18 items, MNA classifies elderly patients as normally fed (score $\geq 24$ ), at risk (score between 17 and 23.5), or as significant malnourishment (score $<17$ ). ${ }^{7}$ The sensitivity and specificity of MNA were $92 \%$ and $86 \%$, respectively, while the sensitivity and specificity of MNA-short form were $94 \%$ and $81 \%$, respectively. The consistency between the clinician assessment and the long and short forms of MNA was found to be at a good level when assessed with kappa statistics (kappa coefficients, 0.68 and 0.66 , respectively). ${ }^{7}$

\section{Statistical analysis}

SPSS 22 program was used in the analysis of the data. The minimum sample size to be achieved was found to be 51 , according to the pilot study results with reference to $80 \%$ power and 95\% CI. Kolmogorow-Smirnov test was used as the normal distribution test. Parametric tests were used for analysis of data with normal distribution, and nonparametric tests were used for analysis of the data without normal distribution. Arithmetic averages have been given in order to provide clarity in the presentation of the results of non-parametric tests that fail to meet the assumptions and to establish integrity with the results of other data. 
In the analysis, Kruskal-Wallis test, Mann-Whitney $U$-test, Student's $t$-test, one-way ANOVA test, Spearman correlation test, chi-squared test, and binary logistic regression test were also used. Significance value was taken as $P<0.05$.

\section{Results}

A total of 105 patients were included in the study. Majority of the patients were male $(92.4 \%)$. The mean age of the study group was $64.6 \pm 10.2$ years. The number of high school graduate patients was found to be low $(8.6 \%)$. Education level of more than $90 \%$ of patients was high school or below. Ninety percent of the patients were married. More than $95 \%$ of the patients had income below the poverty line in the planned period of study, and $75 \%$ were living in the city. Seventy-five percent of the patients had COPD for less than 10 years. Eighty percent of the participants were included in the outpatient clinics; 68 percent of the patients had at least one comorbidity. Ninety percent of the patients were either current smokers or had previously smoked. The mean smoke load of the patients was $52.6 \pm 33.0$ packs/year. The findings regarding the patients' distribution of age, mMRC, GOLD stages, and exacerbation status is given in Table 1 .

About $8.6 \%$ of the patients had BMI lower than $18.5 \mathrm{~kg} / \mathrm{m}^{2}, 24.8 \%$ were obese (BMI above $30 \mathrm{~kg} / \mathrm{m}^{2}$ ), and the rest were in normal to overweight range. When we look at the daily energy taken by the patients and the distribution of the nutrient sources providing this energy, $45.4 \%$ of the

Table I Distribution of the patients according to age groups, mMRC scores, the GOLD categories, and exacerbation status

\begin{tabular}{|c|c|c|}
\hline Age (years) & $\mathbf{n}$ & $\%$ \\
\hline $40-49$ & 7 & 6.7 \\
\hline $50-59$ & 23 & 21.9 \\
\hline $60-69$ & 38 & 36.2 \\
\hline $70-79$ & 30 & 28.6 \\
\hline 80 and above & 7 & 6.7 \\
\hline \multicolumn{3}{|c|}{ mMRC dyspnea scale score } \\
\hline 0 & 0 & 0.0 \\
\hline I & 33 & 31.4 \\
\hline 2 & 23 & 21.9 \\
\hline 3 & 20 & 19.0 \\
\hline 4 & 28 & 26.7 \\
\hline \multicolumn{3}{|l|}{ GOLD category } \\
\hline A & 18 & I7.1 \\
\hline B & 14 & 13.3 \\
\hline C & 15 & 14.3 \\
\hline$\underline{\mathrm{D}}$ & 58 & 55.2 \\
\hline \multicolumn{3}{|l|}{ Exacerbation status } \\
\hline Frequent exacerbations & 73 & 69.5 \\
\hline Infrequent exacerbations & 32 & 30.5 \\
\hline
\end{tabular}

Abbreviations: GOLD, Global Initiative for Chronic Obstructive Lung Disease: mMRC, modified Medical Research Council. average daily energy was obtained from carbohydrates, $16.7 \%$ from proteins, and $37.9 \%$ from fats.

According to the results of the mini nutritional evaluation form, $17 \%$ of the patients had malnutrition, $52.4 \%$ of patients were at risk of malnutrition, and $30.5 \%$ were in normal range. Spirometric variables of the patients according to the nutritional status are shown in Table 2.

When the spirometric variables were compared according to the exacerbation status, $\mathrm{FEV}_{1}$ values were found to be significantly lower in the frequent exacerbators $(P<0.001)$. When the $\mathrm{FEV}_{1}$ and $\mathrm{FEV}_{1} / \mathrm{FVC}$ values were compared according to the patient's BMI, it was found that the spirometric variables of those with the BMI below $18.5 \mathrm{~kg} / \mathrm{m}^{2}$ were significantly lower $(P<0.001$ and $P=0.028$, respectively). The correlations between the muscle volume in the patients' trunk region and fat-free body mass and the spirometric variables are given in Table 3. Both the parameters showed a positive correlation with the spirometric parameters.

When the amount of skeletal muscle was examined according to the malnutrition groups, the amount of skeletal muscle was found to be significantly lower in those who were at risk of malnutrition ( $P=0.001)$. When looking at the relationship between daily average food groups and muscle mass, there was a strong correlation between average daily protein intake and muscle mass (Table 4).

To estimate the malnutrition status, logistic regression analysis was performed for the independent parameters including $\mathrm{mMRC}$, presence of any comorbidity, exacerbation status, disease duration, and $\mathrm{FEV}_{1} / \mathrm{FVC}$ ratios (Table 5). The model fit was calculated to be good (Hosmer and Lemeshow test, $P=0.736$; Omnibus test, $P<0.001$ ). The overall correct estimate of the model was $84 \%$. According to Nagelkerke $\mathrm{R}$ square, $45.8 \%$ of the total change in dependent variable is explained by independent variables.

According to our logistic regression model results, the coefficients of $\mathrm{mMRC}$, presence of any comorbidity, and $\mathrm{FEV}_{1} / \mathrm{FVC}$ variables were found to be significant. The risk of malnutrition was found to be $\sim 23$ times higher in patients with an mMRC score of 3-4 and approximately sevenfold higher in the presence of any comorbidity. The increase in $\mathrm{FEV}_{1} / \mathrm{FVC}$ ratio was found to be 1.11 times more protective. The coefficients of the exacerbation status (frequent and infrequent exacerbators) and disease duration were not statistically significant $(P=0.237$ and $P=0.052$, respectively).

\section{Discussion}

Malnutrition was detected in $17 \%$ of COPD patients in our study group. About $8.6 \%$ of the patients had a BMI below 
Table 2 Spirometric variables according to patients' nutritional status

\begin{tabular}{l|l|l|l|l}
\hline SFT & Normal & $\begin{array}{l}\text { Patients at risk } \\
\text { for malnutrition }\end{array}$ & $\begin{array}{l}\text { Patients with } \\
\text { malnutrition }\end{array}$ & P-value \\
\hline FEV,$(\mathrm{mL})$ & $1,602.6 \pm 675.7$ & $1,483.1 \pm 664.6$ & $846.1 \pm 240.2$ & $\mathbf{0 . 0 0 I}$ \\
FVC $(\mathrm{mL})$ & $2,692.3 \pm 879.3$ & $2,577.5 \pm 832.0$ & $1,773.0 \pm 431.9$ & $\mathbf{0 . 0 0 8}$ \\
FEV $/$ FVC & $57.8 \pm 11.4$ & $55.3 \pm 11.0$ & $46.2 \pm 10.3$ & $\mathbf{0 . 0 0 4}$ \\
FEF25-75 $(\mathrm{mL})$ & $931.0 \pm 586.8$ & $832.0 \pm 600.6$ & $393.3 \pm 19.0$ & $\mathbf{0 . 0 0 3}$ \\
\hline
\end{tabular}

Notes: Presentation of data is mean and standard deviation. $P$-values shown in bold are statistically significant.

Abbreviation: FEF, average forced expiratory flow during the mid (25\%-75\%) portion of the FVC.

$18.5 \mathrm{~kg} / \mathrm{m}^{2}$. When looking at the daily nutritional composition of our patients, average daily energy amount comes $\sim 45 \%$ from carbohydrates, $17 \%$ from proteins, and 38\% from fats. Most of the daily average energy is provided by carbohydrates and proteins. As the mMRC dyspnea score worsened, the frequency of malnutrition increased. As spirometric variables were evaluated in terms of BMI and MNA groups, they were found to be significantly lower in patients with low BMI and malnutrition. Our findings also yielded that, as the average amount of protein taken in the daily diet increased, total muscle mass amount increased. The COPD patients usually have low social status according to average income and education level parameters all over the world. Although this condition was found to be more significant in the region where the study was conducted, our findings were quite similar to those of the previous studies.

In a study to evaluate malnutrition and pulmonary function by Ingadottir et al, the prevalence of malnutrition in COPD patients was found to be $21 \%$, and $57 \%$ of the patients were found to be at risk of malnutrition. It was already shown that the incidence of malnutrition increased as the disease severity of the patients increased. ${ }^{8}$ In another study conducted in 2011 using MNA form and investigating the status of malnutrition in $108 \mathrm{COPD}$ patients by Benedik et al, the prevalence of malnutrition was found as $14 \%$, and also $55 \%$ of patients were found to be at risk of malnutrition. ${ }^{9}$ Collins et al investigated the influence of deprivation on malnutrition risk in 424 COPD patients, and the prevalence of malnutrition

Table 3 Correlations between muscle volume in the trunk region and amount of tissue other than fat and spirometric variables

\begin{tabular}{l|l|l|l|l}
\hline \multirow{2}{*}{$\begin{array}{l}\text { Spirometric } \\
\text { variables }\end{array}$} & \multicolumn{2}{l|}{$\begin{array}{l}\text { Muscle volume in } \\
\text { the trunk region }\end{array}$} & \multicolumn{2}{l}{ Fat-free body mass } \\
\cline { 2 - 5 } & $\boldsymbol{r}$ & $\boldsymbol{P}$-value & $\boldsymbol{r}$ & $\boldsymbol{P}$-value \\
\hline FEV & 0.394 & $<\mathbf{0 . 0 0 I}$ & 0.393 & $<\mathbf{0 . 0 0 I}$ \\
$\mathrm{FVC}$ & 0.354 & $<\mathbf{0 . 0 0 I}$ & 0.354 & $<\mathbf{0 . 0 0 I}$ \\
$\mathrm{FEV}_{1} / \mathrm{FVC}$ & 0.289 & $\mathbf{0 . 0 0 4}$ & 0.285 & $\mathbf{0 . 0 0 4}$ \\
$\mathrm{FEF}^{2} 25 / 75$ & 0.294 & $\mathbf{0 . 0 0 3}$ & 0.293 & $\mathbf{0 . 0 0 3}$ \\
\hline
\end{tabular}

Note: $P$-values shown in bold are statistically significant.

Abbreviation: FEF, average forced expiratory flow during the mid (25\%-75\%) portion of the FVC. was found to be $22 \% .{ }^{10}$ In another study by Gologanu et al, the prevalence of malnutrition in COPD patients was found to be $22.2 \%$. The amount of tissue other than fat in those with low and normal weight was significantly lower than those who were overweight and obese. In the same study, sarcopenia and cachexia were found in $8.3 \%$ of the patients. ${ }^{11}$ In a study using bioelectrical impedance method by Maddocks et al, $\mathrm{FEV}_{1}$ values in patients with low phase angle were found to be significantly lower and the mMRC scores were found to be higher in patients with low phase angle. ${ }^{12}$

In our study, a significant difference was found in terms of BMI and malnutrition groups considering non-fat tissue quantities. The amount of fat-free body mass was found to be significantly lower in those with a low BMI category and in those at malnutrition risk and with malnutrition. The body mass is divided into two parts: fat mass and fat-free mass (FFM). Fat mass is a metabolic inactive energy store. FFM contains the metabolic active organs. Decreased FFM could lead to biologically negative consequences. This claim is supported by epidemiological evidence. ${ }^{13,14}$ There may be systemic consequences due to loss of body mass and loss of FFM in COPD. Systemic inflammation can affect the skeleton and other muscles which can reduce ventilatory capacity. ${ }^{15,16}$ These indicate that total body mass and FFM are important prognostic factors in COPD.

In our study, it was found that one in six patients with COPD had malnutrition, and that approximately half were under the risk of malnutrition. According to the results of the study with MNA and subjective global assessment forms by Yüceege et al, the incidence of malnutrition was found to be $35 \%$ according to MNA and 58\% according to subjective global assessment in male COPD patients. ${ }^{17}$ In this study; when the results of pulmonary function tests were evaluated according to the malnutrition status, it was found that $\mathrm{FEV}_{1}$, $\mathrm{FEV}_{1} / \mathrm{FVC}$, and peak expiratory flow values were significantly lower in patients with malnutrition. ${ }^{17}$ Similar results were obtained in our study too. Our findings yielded that spirometric variables were significantly lower in patients with malnutrition. In addition, the presence of any comorbidity and 
Table 4 Relationship between average amount of nutrient intake and skeletal body mass

\begin{tabular}{|c|c|c|c|c|}
\hline \multirow[t]{2}{*}{ Nutrient intake } & \multicolumn{2}{|c|}{ Body muscle mass (kg) } & \multicolumn{2}{|c|}{ Skeletal muscle mass (kg) } \\
\hline & $r$ & $P$-value & $r$ & $P$-value \\
\hline Daily amount of protein intake $(\mathrm{g})$ & +0.997 & $<0.001$ & +0.995 & $<0.001$ \\
\hline Daily amount of carbohydrate intake (g) & -0.045 & 0.693 & -0.045 & 0.693 \\
\hline Daily amount of fat intake $(\mathrm{g})$ & +0.028 & 0.805 & +0.028 & 0.802 \\
\hline
\end{tabular}

Note: $P$-value and $r$ values shown in bold are statistically significant.

the presence of mMRC dyspnea score of 3-4 increase the risk of malnutrition by sevenfold and 22 -fold, respectively. As a vicious cycle, progression of the disease and increased home dependence lead to further malnourishment, and then malnutrition causes further worsening of the disease severity.

In a study conducted in Turkey, a 10-day low carbohydrate/ high fat diet was prescribed to the COPD patients. After dieting, $\mathrm{FVC}$ values increased significantly and arterial $\mathrm{CO}_{2}$ levels decreased significantly. ${ }^{18}$ However, we could not show any correlation between carbohydrate, fat, and protein levels taken by the patients daily and spirometric parameters. In our study, it was found that there was a significant positive correlation between the amount of protein in the diet content and the amount of muscle mass. As the amount of protein in the diet increased, the amount of skeletal muscle in patients increased significantly. We think that the increased protein content in the diet protects patients from muscle atrophy and cachexia. If there is loss of muscle mass in patients with COPD, muscle tension index will be weaker. Decreased muscle tension could be responsible for the severity of the disease to some extent. As the severity of the disease increases, muscle mass loss becomes more prominent. Morbidity, hospitalization rate, and requirement of ventilator support are also increased in patients with significant muscle mass loss. Muscle mass loss was also found to be an important contributor to mortality in COPD patients independent of lung function, smoking status, and BMI. ${ }^{19,20}$ Weakness of respiratory muscles of any reason, malnutrition, deterioration of gas exchange, cardiac problems, and psychological factors also lead to decreased activity and exercise intolerance.

Table 5 Logistic regression analysis for the parameters related to malnutrition

\begin{tabular}{l|l|l|l}
\hline \multirow{2}{*}{ Parameters } & \multicolumn{3}{l}{ Malnutrition } \\
\cline { 2 - 4 } & $\beta$ & Odds ratio (95\% CI) & P-value \\
\hline mMRC dyspnea scale & 3.131 & $22.888(2.103-249.065)$ & $\mathbf{0 . 0 1 0}$ \\
Comorbidity & 1.946 & $7.004(1.036-47.36 \mathrm{I})$ & $\mathbf{0 . 0 4 6}$ \\
Exacerbation status & $1.45 \mathrm{I}$ & $0.234(0.02 \mathrm{I}-2.592)$ & 0.237 \\
Disease duration & 1.570 & $0.208(0.043-1.016)$ & 0.052 \\
FEV /FVC & -0.107 & $0.898(0.826-0.977)$ & $\mathbf{0 . 0 1 2}$ \\
\hline
\end{tabular}

Note: $P$-values shown in bold are statistically significant. Abbreviation: mMRC, modified Medical Research Council.
These patients are indeed good candidates for pulmonary rehabilitation. If not interrupted with nutritional support, pulmonary rehabilitation, and appropriate medical treatments, patients with COPD who develop malnutrition, muscle mass loss, and muscle weakness enter an unavoidable vicious cycle with the components like decreased quality of life, immobility, and increased exacerbation rates and mortality. ${ }^{21,22}$

The limitations of the present study are that it is a singlecenter study conducted at a university hospital. This condition might have led to a selection bias. However, as a counter balance, the health system in Turkey allows the citizens to apply to any hospital directly. Although we trained the patients about how to fill nutritional forms and checked the nutritional forms and confirmed data on site of documents return, it is certain that there is still a risk that a minority of patients filled the 3-day nutritional form incorrectly. Another limitation worth mentioning could be that the vast majority of our study group had low average income and low education level. Although COPD patients usually have these types of social characteristics, they were found to be more prevalent in our region. So we need further studies to generalize our findings even in COPD patients with significantly higher social status. We should also underline that our sample size was only 105 patients, and we need clinical studies including higher number of patients to make stronger conclusions on the issues addressed in this study.

\section{Conclusion and recommendations}

We found that malnutrition prevalence is high in COPD patients. Our findings showed that malnutrition and low BMI affect the pulmonary function tests negatively and that the amount of protein in the diet content is important to protect the muscle mass. In addition to these, malnutrition was found to be associated with the severity of the disease. We recommend that nutritional status should be evaluated in every COPD patient, and the diet should be tailored individually according to the needs.

\section{Disclosure}

The authors report no conflicts of interest in this work. 


\section{References}

1. Corsonello A, Antonelli Incalzi R, Pistelli R, Pedone C, Bustacchini S, Lattanzio F. Comorbidities of chronic obstructive pulmonary disease. Curr Opin Pulm Med. 2011;17(Supp1 1):S21-S28.

2. Putcha N, Puhan MA, Drummond MB, et al. A simplified score to quantify comorbidity in COPD. PLoS One. 2014;9(12):e114438.

3. Decramer M, Janssens W. Chronic obstructive pulmonary disease and comorbidities. The Lancet Respiratory Medicine [Internet]. Elsevier BV. 2013;1(1):73-83.

4. Tzanakis N, Hillas G, Perlikos F, Tsiligianni I. Managing comorbidities in COPD. Int J Chron Obstruct Pulmon Dis. 2015;95:95.

5. GOLD. GOLD (Global Initiative for Chronic Obstructive Lung Disease) 2017. Pneumologie. 2017;71(1):9-14.

6. Sarıkaya D. Geriatrik Hastalarda Mini Nütrisyonel Değerlendirme (MNA) Testinin Uzun Ve Kisa (MNA-SF) Formunun Geçerlilik Çalışması [A validity study of long and short (MNA-SF) forms of Mini Nutritional Assessment (MNA) test. Geriatric patients internal diseases specialty] [thesis]. Ankara: Hacettepe University; 2013. Turkish.

7. Guigoz Y, Jensen G, Thomas D, Vellas B. The Mini Nutritional Assessment (MNA) review of the literature - What does it tell us? J Nutr Health Aging. 2006;10(6):466.

8. Ingadottir AR, Beck AM, Baldwin C, et al. PT07.1: Two Components of the New ESPEN Diagnostic Criteria for Malnutrition are Independent Predictors of Lung Function in Hospitalized Patients with Chronic Obstructive Pulmonary Disease (COPD). Clin Nutr. 2017; 36:S43-S44.

9. Benedik B, Farkas J, Kosnik M, Kadivec S, Lainscak M. Mini nutritional assessment, body composition, and hospitalisations in patients with chronic obstructive pulmonary disease. Respir Med. 2011;105(Suppl 1): S38-S43.

10. Collins PF, Elia M, Kurukulaaratchy RJ, Stratton RJ. The influence of deprivation on malnutrition risk in outpatients with chronic obstructive pulmonary disease (COPD). Clin Nutr. 2018;37(1):144-148.

11. Gologanu D, Ionita D, Stanescu C, Raceanu AM, Bogdan MA. Changes over time in body composition assessed by segmental bioelectrical impedance analysis in COPD patients. Eur Respir Soc. 2015;46(suppl 59): PA3068.
12. Maddocks M, Kon SS, Jones SE, et al. Bioelectrical impedance phase angle relates to function, disease severity and prognosis in stable chronic obstructive pulmonary disease. Clin Nutr. 2015;34(6):1245-1250.

13. Heitmann BL, Erikson H, Ellsinger BM, Mikkelsen KL, Larsson B. Mortality associated with body fat, fat-free mass and body mass index among 60-year-old swedish men-a 22-year follow-up. The study of men born in 1913. Int J Obes Relat Metab Disord. 2000;24(1):33-37.

14. Bigaard J, Frederiksen K, Tjønneland A, et al. Body fat and fat-free mass and all-cause mortality. Obes Res. 2004;12(7):1042-1049.

15. Agustí AG, Noguera A, Sauleda J, Sala E, Pons J, Busquets X. Systemic effects of chronic obstructive pulmonary disease. Eur Respir J. 2003;21(2):347-360.

16. Agustí AG, Sauleda J, Miralles C, et al. Skeletal muscle apoptosis and weight loss in chronic obstructive pulmonary disease. Am J Respir Crit Care Med. 2002;166(4):485-489.

17. Yuceege MB, Salman SO, Duru S, Saygıdeğer Y, Sonmez Z, Ardıç S. The Evaluation of Nutrition in Male COPD Patients Using Subjective Global Assessment and Mini Nutritional Assessment. Int J Intern Med. 2013;2(1):1-5.

18. Aydın Tosun G, Umut S, Yıldırım N, Hacıbekiroğlu A, Şahin G, Yücel R. The effect of low carbohydrate/high fat diet on respiratory function in patients with chronic obstructive pulmonary disease (COPD). Cerrahpaşa J Med. 1998;29(3):119122.

19. Swallow EB, Reyes D, Hopkinson NS, et al. Quadriceps strength predicts mortality in patients with moderate to severe chronic obstructive pulmonary disease. Thorax. 2007;62(2):115-120.

20. Man WD, Soliman MG, Nikoletou D, et al. Non-volitional assessment of skeletal muscle strength in patients with chronic obstructive pulmonary disease. Thorax. 2003;58(8):665-669.

21. Lemire BB, Theriault ME, Dube A, Maltais F, Debigare R. The Effect Of Oxidative Stress On MAPK Activation In Human Skeletal Myotubes From Patients With Chronic Obstructive Pulmonary Disease. American Journal of Respiratory and Critical Care Medicine. 2012;185:A5315.

22. Hodson M. The nurse role in addressing malnutrition in COPD patients. Pract Nurs. 2016;27(10):502-504.
International Journal of COPD

\section{Publish your work in this journal}

The International Journal of COPD is an international, peer-reviewed journal of therapeutics and pharmacology focusing on concise rapid reporting of clinical studies and reviews in COPD. Special focus is given to the pathophysiological processes underlying the disease, intervention programs, patient focused education, and self management protocols.

\section{Dovepress}

This journal is indexed on PubMed Central, MedLine and CAS. The manuscript management system is completely online and includes a very quick and fair peer-review system, which is all easy to use. Visit $\mathrm{http}: / /$ www.dovepress.com/testimonials.php to read real quotes from published authors. 